\title{
Simultaneous Treatment of COVID-19 With Serine Protease Inhibitor Camostat and/or Cathepsin L Inhibitor?
}

\author{
Stefan Bittmann ${ }^{\mathrm{a}, \mathrm{b}}$, Anne Weissenstein ${ }^{\mathrm{a}}$, Gloria Villalon ${ }^{\mathrm{a}}$, \\ Elena Moschuring-Alieva ${ }^{a}$, Elisabeth Luchter ${ }^{a}$
}

\section{To the Editor}

Severe acute respiratory syndrome coronavirus 2 (SARSCoV-2) binds to angiotensin II receptor in different tissues of the body, especially in the mouth cavity and the tongue and the skin $[1,2]$. Therefore, it needs the serine protease, transmembrane serine protease 2 (TMPRSS2), for cell entry [2]. Cathepsin L/B (CTSL/CTSB) plays an important role in a second pathway, the endosomal pathway.

\section{SARS-CoV-2 binds to angiotensin II receptor (angiotensin converting enzyme 2 (ACE-2))}

Based on the newest results of the research, the new coronavirus uses the protein ACE-2 as a receptor for docking to pneumocyte type II [2]. A broadly put up team under the direction of infection biologists of the German Primate Centre and with participation of the Charite Berlin, the Endowment Veterinary College of Hannover, the Accident Clinic BG Murnau which wanted to find out Munich LMU, the Robert of Koch's Institute and the German Centre for Infection researched how SARS-CoV-2 penetrates into lung cells and how this process can be blocked [3]. They have published their results in the magazine Cell [3]. They also identified the TMPRSS2 as responsible cellular protein for the entry into the cell [3]. The type II transmembrane protease pro-TMPRSS2 activates the spike (S) protein of SARS-CoV on the cell surface after the recipient, which binds in cells during virus access. Without TMPRSS2, SARS-CoV-2 reaches cell access via an endosomal pathway, in which CTSL can plays an important role with the activation of the $\mathrm{S}$ protein fusogenicity.

\section{SARS-CoV-2 needs for cell entry ACE-2, TMPRSS2 and CTSL}

Substantially for the entry, the control of S protein of the virus

Manuscript submitted April 9, 2020, accepted April 21, 2020

${ }^{a}$ Department of Pediatrics, Ped Mind Institute (PMI), Gronau, Germany ${ }^{b}$ Corresponding Author: Stefan Bittmann, Department of Pediatrics, Ped Mind Institute (PMI), Hindenburgring 4, D-48599 Gronau, Germany.

Email: stefanbittmann@gmx.de

doi: https://doi.org/10.14740/jocmr4161 is by presence of serine protease TMPRSS2 and CTSL. TMPRSS2 activates S protein for cell-cell and virus-cell fusion in transformation only. The $\mathrm{S}$ protein is fusogenetically activated by CTSL, therefore allowing fusion of the viral and endosomal membranes. Subsequent infection is sensitive to inhibitors of endosomal acidification such as ammonium chloride, suggesting that SARS-CoV-2 requires a low-pH milieu for infection. On the other hand, $\mathrm{S}$ protein can mediate cell-cell fusion at neutral $\mathrm{pH}$, indicating that $\mathrm{S}$ protein-mediated fusion does not include an absolute requirement for an acidic environment. Given these discordant findings, we hypothesized that cellular factors sensitive to ammonium chloride, such as $\mathrm{pH}$-dependent endosomal proteins, may play a role in mediating SARS-CoV-2 viral entry. The requirements for proteases in the activation of viral infectivity and the effect of protease inhibitors on COVID-19 infection are examined. Our results are consistent with a model in which SARS-CoV-2 employs a unique three-step method for membrane fusion, involving receptor binding and induced conformational changes in $\mathrm{S}$ glycoprotein followed by CTSL proteolysis and activation of membrane fusion within endosomes.

\section{TMPRSS2}

TMPRSS2 encodes a protein that belongs to the serine protease family. The encoded protein contains a type I transmembrane area, a receiver classified one area, a garbage collector receiver cysteine-rich area and a pro-sweep area. Serine provokes are known to be involved in many physiological and pathological processes. This gene was demonstrated to be regulated by androgenic hormones in prostate cancer cells and regulated in androgen-independent prostate cancer tissue. It is thought that the pro-inflammatory area of this protein is cleaved and hidden in the cell media after auto splitting. Alternately split transcript variants that encode different isoforms have been found for this gene.

\section{Camostat}

Camostat (mesylate) is supplied as a crystalline solid. A stock solution can be prepared by dissolving the camostat (mesylate) in the solvent of choice, which should be purged with an inert gas. The camostat (mesylate) is soluble in organic solvents such as dimethyl sulfoxide (DMSO) and dimethylformamide. 
Table 1. Different Therapeutic Approaches to Treat COVID-19

\begin{tabular}{|c|c|c|}
\hline Classes & Treatment option & \\
\hline \multirow[t]{2}{*}{ Anti-viral drug } & $\begin{array}{l}>85 \% \text { of patients received antiviral drugs, including oseltamivir ( } 75 \\
\text { mg every } 12 \mathrm{~h} \text { orally), ganciclovir }(0.25 \mathrm{~g} \text { every } 12 \mathrm{~h} \text { intravenously) } \\
\text { and lopinavir/ritonavir tablets ( } 400 / 100 \mathrm{mg} \text { twice daily); lopinavir/ } \\
\text { ritonavir sirup in children; remdesivir is currently in trials in more than } \\
10 \text { medical facilities in Wuhan and is known to prevent MERS-CoV-2 }\end{array}$ & In trials \\
\hline & Ribonucleoside analog NHC (EIDD-1931) [10] & In vitro \\
\hline Herbal agent & $\begin{array}{l}\text { During the last SARS-CoV outbreak, traditional Chinese medicine was } \\
\text { widespread and is currently used in China. The five most commonly } \\
\text { used herbs were Astragali Radix (Huangqi), Glycyrrhizae Radix and } \\
\text { Rhizoma (Gancao), Saposhnikoviae Radix (Fangfeng), Atractylodis } \\
\text { Macrocephalae Rhizoma (Baizhu) and Lonicerae Japonicae Flo }\end{array}$ & Add-on therapy \\
\hline CD147 inhibitor & Meplazumab [7] & Add-on therapy [7] \\
\hline $\begin{array}{l}\text { MC antibody treatment/ } \\
\text { mesenchymal stem cell TX }\end{array}$ & $\begin{array}{l}\text { Monoclonal antibodies against } \mathrm{S} \text { protein, } \\
\text { against ACE-2, against viral protein }\end{array}$ & In trials \\
\hline
\end{tabular}

NHC: $\beta$-D-N4-hydroycytidine; TMPRSS2: transmembrane serine protease 2; ACE-2: angiotensin converting enzyme 2; MERS-CoV: Middle East respiratory syndrome coronavirus; SARS-CoV: severe acute respiratory syndrome coronavirus.

The solubility of camostat (mesylate) in these solvents is about $25 \mathrm{mg} / \mathrm{mL}$. Camostat is a protease inhibitor [3, 4]. It inhibits trypsin $(\mathrm{Ki}=1 \mathrm{nM})$ and various inflammatory proteases, including plasmin, kallikrein and thrombin. Camostat inhibits the incorporation of the SARS-CoV and the surface glycoprotein COVID-19 into pseudotyped particles of vesicular stomatitis virus (VSV) in Vero cells, Calu-3 cells and primary human lung epithelial cells when administered at a concentration of $10 \mu \mathrm{M}$ [4]. It reduces the number of genomic equivalents of SARS-CoV-2, a marker of infection, in Calu-3 cells. Camostat inhibits the function of the sodium channel in human respiratory epithelial cells $(\mathrm{IC} 50=50 \mathrm{nM})$ and improves mucociliary clearance in sheep [4]. Administration of camostat (1 mg/ $\mathrm{kg}$ ) inhibits the production of tumor necrosis factor- $\alpha$ (TNF- $\alpha$ ) and monocyte chemoattractant protein- 1 by monocytes and the proliferation of pancreatic star cells in a rat model of pancreatic fibrosis [2]. Camostat is in Japan well known as "Foipan". In Japan, camostat is certified for patients with chronic pancreatitis and showed attenuating effect in pancreatic fibrosis [5]. For SARS-CoV-2 the first clinical trials were initiated at the University of Aarhus, Denmark. Camostat has the potential to block the entry of the virus into the lung cells, well known as pneumocytes type 2 . To date, no clinical studies were performed, nor any results are present. What we know is that camostat could have a promising potential in COVID-19.

\section{CTSL inhibitor}

SARS-CoV-1 used CTSL, and infection could be blocked by
CTSL inhibitors in mouse model [6]. SARS-CoV-2 could be blocked in a similar way; therefore, clinical trials should be performed as soon as possible with CTSL inhibitors in COVID-19.

\section{Conclusions}

To date, many different treatment options are used "off-label" in severe cases or are under clinical trial. Table 1 shows the different therapeutic approaches to treat COVID-19. In this work, we focus on serine protease inhibitor camostat, which partially blocks infection by SARS-CoV-2 [2, 3, 7-10]. Simultaneous treatment of the cells with camostat and a cathepsin inhibitor has efficiently prevented both cell access and multi-step growth of SARS-CoV-2 in human Calu-3 weather pathway epithelial cells [11]. This efficient inhibition could be attributed to the double blockade of access from the cell surface and through the endosomal pathway. These observations suggest camostat as a candidate antiviral drug to prevent or suppress TMPRSS2dependent infection by the SARS-CoV-2 $[8,9]$. Further investigations are necessary. A new therapy option in COVID-19 patients is based on the combination of camostat (serine protease TMPRSS2 inhibitor) and a cathepsin inhibitor [5, 6]. First clinical off-label trials should be performed as soon as possible in COVID-19 patients. In a recent study, an orally bioavailable broad-spectrum antiviral, ribonucleoside analog $\beta$-D-N4hydroycytidine (NHC, EIDD-1931), showed positive results of inhibiting SARS- CoV-2 in human airway epithelia cell cultures and multiple coronaviruses in mice [10]. Further trials 
pointed out the role of a new receptor in COVID-19 pathology, the CD147 receptor (basigin, EMMRIN). CD 147 receptor can be blocked by meplazumab as add-on therapy and needs further prospective trials to classify the role in COVID-19 treatment, especially in cytokine release syndrome $[7,12]$.

\section{Acknowledgments}

None to declare.

\section{Financial Disclosure}

None to declare.

\section{Conflict of Interest}

None to declare.

\section{Informed Consent}

Not applicable.

\section{Author Contributions}

All authors contributed to this work and proved the available data and final manuscript.

\section{Data Availability}

The authors declare that data supporting the findings of this study are available within the article.

\section{References}

1. Xu H, Zhong L, Deng J, Peng J, Dan H, Zeng X, Li T, et al. High expression of ACE2 receptor of 2019-nCoV on the epithelial cells of oral mucosa. Int J Oral Sci.
2020;12(1):8.

2. Bittmann S. The role of Angiotensin-2 receptor in transmission process. J Regen Biol Med. 2020;2(1):1-2.

3. Hoffmann M, Kleine-Weber H, Schroeder S, Kruger N, Herrler T, Erichsen S, Schiergens TS, et al. SARS-CoV-2 Cell Entry Depends on ACE2 and TMPRSS2 and Is Blocked by a Clinically Proven Protease Inhibitor. Cell. 2020;181(2):271-280 e278.

4. Coote K, Atherton-Watson HC, Sugar R, Young A, MacKenzie-Beevor A, Gosling M, Bhalay G, et al. Camostat attenuates airway epithelial sodium channel function in vivo through the inhibition of a channel-activating protease. J Pharmacol Exp Ther. 2009;329(2):764-774.

5. Gibo J, Ito T, Kawabe K, Hisano T, Inoue M, Fujimori N, Oono $\mathrm{T}$, et al. Camostat mesilate attenuates pancreatic fibrosis via inhibition of monocytes and pancreatic stellate cells activity. Lab Invest. 2005;85(1):75-89.

6. Simmons G, Gosalia DN, Rennekamp AJ, Reeves JD, Diamond SL, Bates P. Inhibitors of cathepsin L prevent severe acute respiratory syndrome coronavirus entry. Proc Natl Acad Sci U S A. 2005;102(33):11876-11881.

7. Bian H, Zheng ZH, Wei D, Zhang Z et al. Meplazumab treats COVID-19 pneumonia: an open labelled, concurrent controlled add-on clinical trial. med Rxiv. 2020.

8. Bittmann S, Luchter E, Moschuring-Alieva E, Villalon G, Weissenstein A. COVID 19: Camostat and the role of serine protease entry inhibitor TMPRSS2. J Regen Biol Med. 2020;2(2):1-2.

9. Bittmann S, Luchter E, Weissenstein A, Villalon G, Moschuring- Alieva E. TMPRSS2-Inhibitors Play a role in Cell Entry Mechanism of COVID-19: An Insight into Camostat and Nefamostat. J Regen Biol Med. 2020;2(2):13.

10. Sheahan TP, Sims AC, Zhou S, Graham RL, Pruijssers AJ, Agostini ML, Leist SR, et al. An orally bioavailable broad-spectrum antiviral inhibits SARS-CoV-2 in human airway epithelial cell cultures and multiple coronaviruses in mice. Sci Transl Med. 2020.

11. Simmons G, Reeves JD, Rennekamp AJ, Amberg SM, Piefer AJ, Bates P. Characterization of severe acute respiratory syndrome-associated coronavirus (SARS-CoV) spike glycoprotein-mediated viral entry. Proc Natl Acad Sci U S A. 2004;101(12):4240-4245.

12. Moore BJB, June CH. Cytokine release syndrome in severe COVID-19. Science. 2020. 